
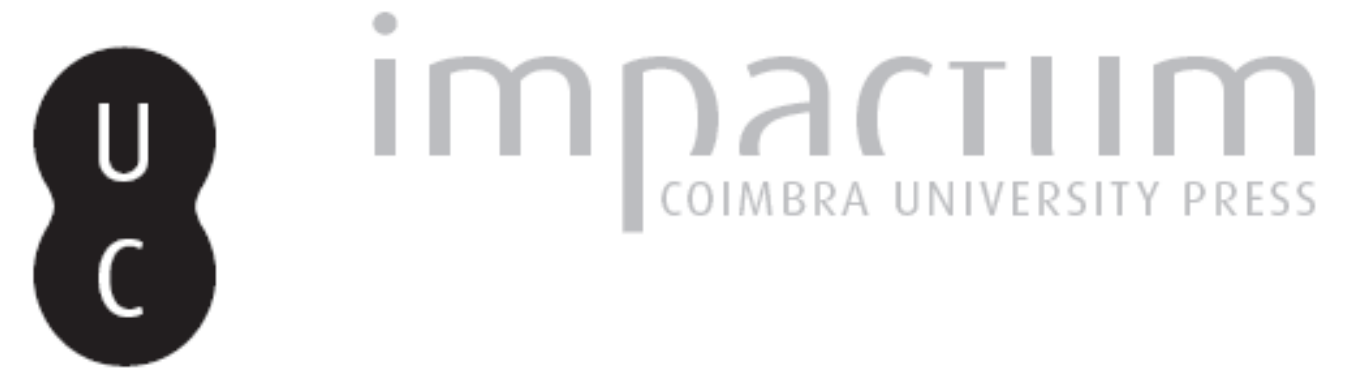

\title{
História intelectual e a longa duração: a Guerra Civil em perspetiva
}

\section{Autor(es): $\quad$ Armitage, David}

Publicado por: Imprensa da Universidade de Coimbra

URL persistente:

URI:http://hdl.handle.net/10316.2/40207

DOI:

DOI:https://doi.org/10.14195/2183-8925_34_1

Accessed : $\quad$ 26-Apr-2023 12:47:25

A navegação consulta e descarregamento dos títulos inseridos nas Bibliotecas Digitais UC Digitalis, UC Pombalina e UC Impactum, pressupõem a aceitação plena e sem reservas dos Termos e Condições de Uso destas Bibliotecas Digitais, disponíveis em https://digitalis.uc.pt/pt-pt/termos.

Conforme exposto nos referidos Termos e Condições de Uso, o descarregamento de títulos de acesso restrito requer uma licença válida de autorização devendo o utilizador aceder ao(s) documento(s) a partir de um endereço de IP da instituição detentora da supramencionada licença.

Ao utilizador é apenas permitido o descarregamento para uso pessoal, pelo que o emprego do(s) título(s) descarregado(s) para outro fim, designadamente comercial, carece de autorização do respetivo autor ou editor da obra.

Na medida em que todas as obras da UC Digitalis se encontram protegidas pelo Código do Direito de Autor e Direitos Conexos e demais legislação aplicável, toda a cópia, parcial ou total, deste documento, nos casos em que é legalmente admitida, deverá conter ou fazer-se acompanhar por este aviso.

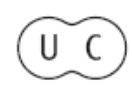



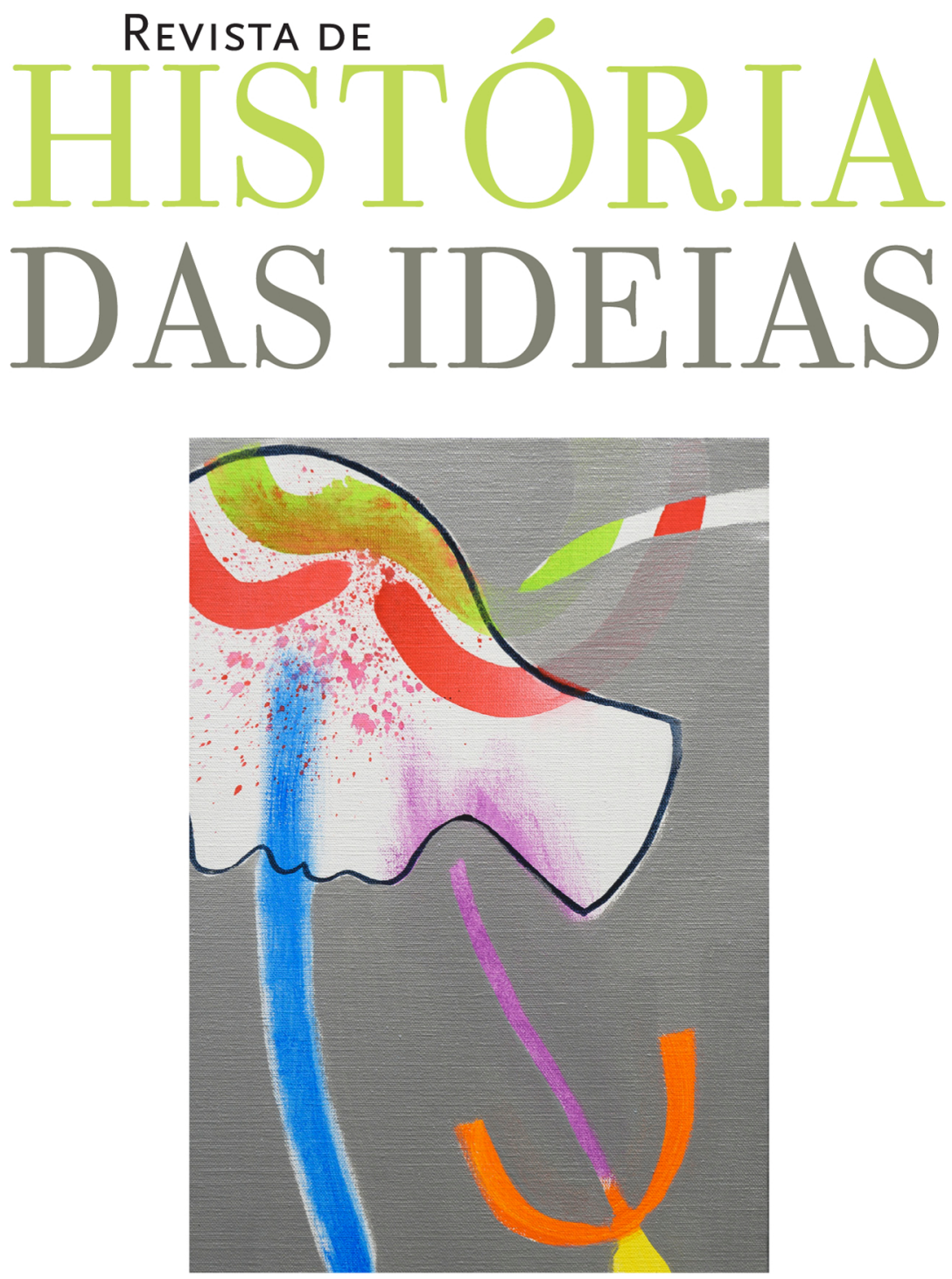

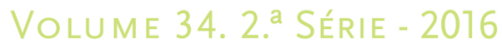




\title{
HISTÓRIA INTELECTUAL E A LONGA DURAÇÃO: A GUERRA CIVIL EM PERSPETIVA*
}

\section{INTELLECTUAL HISTORY AND THE LONGUE DURÉE: CIVIL WAR IN PERSPECTIVE}

\author{
DAVID ARMitage \\ armitage@fas.harvard.edu \\ University of Harvard \\ Texto recebido em / Text submitted on: 08/06/2016 \\ Texto aprovado em / Text approved on: 21/07/2016
}

\section{Resumo:}

Após décadas de aversão e esquecimento, historiadores de todos os quadrantes começam a regressar aos estudos de grande escala temporal. Há até sinais de que os historiadores intelectuais estão a retomar a abordagem de longa duração. Quais serão as razões para este ressurgimento da história intelectual de grande alcance e de que modo pode ela tornar-se metodologicamente robusta e, ao mesmo tempo, historicamente convincente? Este artigo propõe um modelo de história transtemporal baseado num contextualismo seriado para criar uma «história nas ideias» («history in ideas») que englobe séculos ou até milénios. Alguns exemplos-chave são retirados de trabalhos em desenvolvimento focados em ideias sobre a guerra civil vista desde

* Este artigo é uma versão revista da Annual Nicolai Rubinstein Lecture sobre História do Pensamento Político e História Intelectual, apresentada na Queen Mary University of London a 29 de março de 2012. Agradeço em particular a Richard Bourke, Jo Guldi, Jim Kloppenberg, Darrin McMahon, Sophie Rosenfeld e Quentin Skinner pelos seus comentários e encorajamento. Tradução para português de Samuel Alexandre. 
a Roma antiga até à atualidade. $\mathrm{O}$ artigo conclui com uma breve reflexão sobre o impacto potencial das humanidades digitais na prática da história intelectual.

\title{
Palavras-chave:
}

Escola de Cambridge, guerra civil, história conceptual, humanidades digitais, longa duração.

\begin{abstract}
:
Historians of all kinds are beginning to return to temporally expansive studies after decades of aversion and neglect. There are even signs that intellectual historians are returning to the longue durée. What are the reasons for this revival of long-range intellectual history? And how might it be rendered methodologically robust as well as historically compelling? This article proposes a model of transtemporal history, proceeding via serial contextualism to create a history in ideas spanning centuries, even millennia: key examples come from work in progress on ideas of civil war from ancient Rome to the present. The article concludes with brief reflections on the potential impact of the digital humanities on the practice of intellectual history.
\end{abstract}

\section{Keywords:}

Cambridge School, civil war, conceptual history, digital humanities, longue durée.

Em muitos domínios da escrita histórica, retomou-se a abordagem de grande escala. Nalgumas áreas, tais como a arqueologia histórica, a sociologia comparativa ou a teoria de sistemas mundiais, esta abordagem nunca foi abandonada. Noutros ramos, ela desapareceu para não mais voltar: é pouco provável que voltem a ser imitadas as histórias universais e de alcance global associadas a Oswald Spengler e Arnold Toynbee, pelo menos sob a forma de projetos de uma vida e de vários volumes escritos por autores singulares motivados por uma visão abrangente da civilização ${ }^{(1)}$. Em toda a profissão de historiador, o telescópio tem suplantado o microscópio como o instrumento de análise predileto e o plano geral tem vindo a substituir o primeiro plano como o tipo mais dominante de retrato do passado. Porém,

(1) David Christian, «The Return of Universal History», History and Theory, 49 (2010), p. 6-27. 
a análise de primeiro plano não foi de modo algum abandonada, como bem o comprovam a popularidade continuada da biografia e a utilidade da micro-história. Ainda assim, este tipo de análise está a ser complementado por panoramas alargados no tempo e no espaço, e apresentados sob várias designações: «world history», «deep history» e «big history». Este regresso à longa duração coloca desafios e oferece oportunidades para todos os historiadores ${ }^{(2)}$. Neste artigo, analisarei as suas implicações na prática da história intelectual.

Na sua versão mais ambiciosa, a «big history» - assim designada pelos seus profissionais e responsáveis pela fundação da International Big History Association - remonta ao próprio Big Bang ${ }^{(3)}$. Esta é uma história universal consubstancial ao próprio universo e que se baseia nas descobertas da cosmologia, astronomia, geologia e da biologia evolutiva, bem como em disciplinas históricas mais convencionais como a arqueologia e a sociologia histórica. Em contrapartida, a «deep history» é relativamente estreita, no sentido em que apenas se foca na história dos seres humanos. Define-se como "profunda» sobretudo por quebrar a barreira entre a «pré-história» e a história no sentido convencional de história documentada, sendo o passado recuperável por meio de vários textos com significado produzidos por agentes que os legaram ao futuro ${ }^{(4)}$. Este tipo de história baseia-se na genética, na neurofisiologia e na biologia evolutiva, entre outros ramos do saber. Tal como a «big history», de ainda maior alcance, a «deep history» vê a história consciente dos seres humanos como um fenómeno relativamente breve e em continuidade com os desenvolvimentos que em muito antecederam a capacidade de a espécie humana se historiar. Por outro lado, os historiadores «globais» parecem relativamente pouco ambiciosos, visto que geralmente se limitam a um período de tempo ainda mais reduzido, abrangendo milhares em vez de dezenas de milhares ou mesmo milhares de milhões de anos.

(2) Para reflexões mais alargadas sobre as implicações deste movimento, veja-se Ignacio Olabarri, «'New' New History: A Longue Durée Structure», History and Theory, 34 (1995), p. 1-29; Barbara Weinstein, «History Without a Cause? Grand Narratives, World History, and the Postcolonial Dilemma», International Review of Social History, 50 (abril 2005), p. 71-93; David Armitage e Jo Guldi, «The Return of the Longue Durée» (no prelo).

(3) David Christian, Maps of Time: An Introduction to Big History, nova ed., Berkeley, University of California Press, 2011.

(4) Daniel Lord Smail, On Deep History and the Brain, Berkeley, University of California Press, 2008; Andrew Shryock e Daniel Lord Smail (eds.), Deep History: The Architecture of Past and Present, Berkeley, University of California Press, 2011. 
Estes historiadores focam-se no Antropoceno, o período durante o qual os humanos moldaram e foram moldados pelo seu ambiente ${ }^{(5)}$.

Sob todas as suas formas, a «big history» tem-se revelado um terreno inóspito para as questões do significado e intenção que estão no centro da história intelectual. Tal não se deve simplesmente ao motivo banal de os historiadores da «big history» geralmente investigarem uma fatia mínima da história documentada no final das suas grandes análises; como Mark Twain notou humildemente: «Se a Torre Eiffel representasse agora a idade do mundo, a camada de tinta no extremo do seu pináculo representaria a fração humana dessa mesma idade» ${ }^{(6)}$. A justificação também não se encontra no facto de a ação humana perder significado face ao tempo cosmológico ou até arqueológico. A explicação reside, pelo menos neste momento, no materialismo na base das duas principais correntes da «big history», que poderemos designar como tendências biologistas e economicistas.

A tendência biologista, bem representada na obra On Deep History and the Brain (2008) de Daniel Lord Smail, meu colega de Harvard, é neurofisiologicamente redutora: ao afirmar que todas as ações humanas, incluindo o pensamento e a cultura, podem ser explicadas pela química cerebral, Smail aproxima as reflexões dos reflexos ${ }^{(7)}$. Na corrente economicista, exemplificada de modo esclarecedor na obra Why the West Rules - For Now (2010) de Ian Morris, um classicista da Universidade de Stanford, o intelecto é equiparado aos interesses. No estimulante relato de Morris sobre a «configuração» da história humana, abrangendo vários milénios, cada idade simplesmente «cria o pensamento de que necessita». Por exemplo, o Budismo, o Cristianismo e o Islão na Era Axial resumemse da mesma maneira: são simplesmente o produto da capacidade de resolução de problemas de uma espécie de chimpanzés inteligentes, mas necessitados ${ }^{(8)}$. Neste sentido, pelo menos quando analisa as questões de

(5) Patrick Manning, Navigating World History: A Guide for Researchers and Teachers, Nova Iorque, Palgrave Macmillan, 2003; P. Manning (ed.), World History: Global and Local Interactions, Princeton, NJ, M. Wiener, 2006; Dipesh Chakrabarty, «Postcolonial Studies and the Challenge of Climate Change», New Literary History, 43 (2012), p. 1-18.

(6) Mark Twain, «The Damned Human Race» (1903), citado em Christian, Maps of Time, p. 5.

(7) Smail, On Deep History and the Brain; para um exemplo de historia intelectual usada neste sentido, veja-se Lynn Hunt, Inventing Human Rights: A History, Nova Iorque, W. W. Norton, 2007, p. 32-34 et passim.

(8) Ian Morris, Why the West Rules - For Now: The Patterns of History, and What They Reveal About the Future, Londres, Profile Books, 2010, p. 420, 476, 568, 621. 
maior importância para os historiadores intelectuais, a «deep history» pode parecer algo superficial.

Os franceses da escola dos Annales, os primeiros historiadores a adotar a abordagem da longa duração, não estavam muito mais recetivos às preocupações da história intelectual. Existiram exceções notáveis como a de Lucien Febvre, cuja obra Le problème de l'incroyance au XVIe siècle (1942) abordava o impensável em detrimento da matéria pensada. Contudo, o mesmo Febvre mostrou-se muito crítico da história da filosofia elaborada por Ernst Cassirer, Raymond Klibansky e outros, referindo-se a esta como: «conceitos criados, pode supor-se, por intelectos incorpóreos vivendo uma vida completamente irreal na esfera das ideias puras» ${ }^{(9)}$. No seu ensaio clássico sobre a longa duração, Fernand Braudel expressou admiração por obras-primas escritas por historiadores culturais e literários como Ernst Robert Curtius e o próprio Febvre, embora as visse na prática como mitografias, estudos de continuidades imóveis e até imutáveis nas quais «os esquemas mentais eram também prisões da longa duração» ${ }^{(10)}$. A história intelectual teria de ser englobada numa história de mentalidades que fossem, por definição, coletivas - abordando os hábitos de um indivíduo «em comum com os de outros homens do seu tempo»bem como diacrónicas e, consequentemente, «relativamente imóveis» ${ }^{(11)}$.

Os exemplos fornecidos por Braudel para estes elementos duradouros da aparelhagem mental coletiva e imutável incluíam a ideia de cruzada, a prática do espaço pictórico geométrico e um «conceito aristotélico do universo» que só foi destronado com a Revolução Científica. Segundo Braudel, estes elementos estavam sujeitos ao mesmo imperativo de «permanência e sobrevivência» que caraterizava as vidas dos pastores transumantes, aprisionados pelos ciclos rítmicos dos seus rebanhos, ou de áreas urbanas fixadas pelas suas topografias e geografias. Do mesmo modo, considerou-os independentes das ruturas e inversões que tinham

(9) Lucien Febvre, Le problème de l'incroyance au XVIe siècle, la religion de Rabelais, Paris, A. Michel, 1942; «[...] concepts issus, pourrait-on croire, d'intelligences désincarnées et vivant, d'une vie toute irréelle, dans la sphére des idées pures»: Lucien Febvre, «Puissance et declin d'une croyance», Annales d'Histoire Économique et Sociale, 9 (1937), p. 89.

(10) «[...] les cadres mentaux, aussi, sont prisons de longue durée»: Fernand Braudel, «Histoire et Sciences sociales. La longue durée», Annales E.S.C., 13 (1958), p. 731, 732.

(11) Roger Chartier, «Intellectual History or Sociocultural History? The French Trajectories», in Dominick LaCapra e Steven L. Kaplan (eds.), Modern European Intellectual History: Reappraisals and New Perspectives, Ithaca, Cornell University Press, 1982, p. 22 (citando Jacques Le Goff), 25. 
lugar ao nível da história dos acontecimentos. Tal como definida pelos historiadores da escola dos Annales, a longa duração era, pois, terreno infértil para os historiadores intelectuais. Franco Venturi define a abordagem da longa duração da seguinte forma: «Examina-se toda a estrutura 'geológica' do passado, mas não o solo no qual as ideias germinam e crescem» ${ }^{(12)}$.

Ao mesmo tempo que os historiadores da longa duração rejeitavam a história intelectual, os historiadores intelectuais vacinavam-se contra a abordagem de longa duração. No seu artigo clássico de 1969, «Meaning and Understanding in the History of Ideas», Quentin Skinner criticou a história das ideias e outros projetos histórico-intelectuais de grande alcance defendidos por Arthur Lovejoy (como o ensino de clássicos da literatura na teoria política) por transformarem ideias em entidades com histórias de vida, mas desprovidas de substância, por ignorarem a ação humana e negarem a intenção e, acima de tudo, criarem «uma história não de ideias mas de abstrações: uma história de pensamentos que nunca ninguém conseguiu ter, a um nível de coerência que nunca ninguém atingiu». Uma metodologia tão inepta foi acusada de dar auxílio e alento a todos aqueles - em especial aos cientistas políticos-que abstraíam argumentos dos seus contextos para recuperar uma sabedoria intemporal: por um lado, por estar desvinculada de momentos específicos de utilização estratégica e, por outro lado, por ter perdurado por vastas extensões de tempo, muitas vezes desde a Antiguidade (ocidental) até ao presente. Skinner concluiu que «tais histórias podem correr mal, mas nunca correm bem». A solução que propôs para este conjunto de erros foi uma contextualização retórica e temporal ainda mais estrita, através de uma conceção das ideias como argumentos e dos argumentos como movimentos dentro de jogos de linguagem ${ }^{(13)}$.

Os historiadores intelectuais, pelo menos no mundo anglófono, passariam a focar-se nas abordagens sincrónicas e de curto prazo, em detrimento das abordagens diacrónicas e de longo prazo. O seu foco nos agentes individuais e suas intenções distanciava-se consideravelmente dos procedimentos agregadores e de anonimato de uma história seriada das mentalidades. A sua atenção crucial aos atos de fala, desenvolvida

(12) Braudel, «La longue durée», p. 732; Franco Venturi, Utopia and Reform in the Enlightenment, Cambridge, 1971, p. 14.

(13) Quentin Skinner, «Meaning and Understanding in the History of Ideas», History and Theory, 8 (1969), p. 18, 35. 
dentro da tradição filosófica mais analítica de J. L. Austin e Ludwig Wittgenstein, impediu durante muito tempo qualquer intercâmbio com a escola da Begriffs geschichte, de maior alcance temporal e baseada numa articulação fundamentalmente heideggeriana das continuidades entre passado, presente e futuro ${ }^{(14)}$. Assim, a separação entre a história intelectual e a longa duração parecia completa e irreversível, visto que os historiadores da longa duração renegavam a história intelectual e esta seria desde então praticada em oposição à longa duração.

Graças a esta repulsa mútua, a ideia de história intelectual de longa duração foi até há pouco tempo um oximoro, uma quase impossibilidade que encerrava um profundo erro moral. Contudo, a primeira lei da dinâmica académica dita que para cada ação há uma reação: deitam-se fora os bebés com a água do banho, mas eles têm uma capacidade fantástica de se porem de novo em pé. Nos últimos anos, começaram novamente a surgir histórias intelectuais de durações cada vez mais alargadas. Tenho em mente obras com registos muito diferentes, desde Sources of the Self (1989) de Charles Taylor, que põe levemente a história ao serviço de uma narrativa, passando por Songs of Experience (2005) de Martin Jay, The Idea of the Self (2005) de Jerrold Seigel, Happiness: A History (2006) de Darrin McMahon's, Objectivity (2007) de Lorraine Daston e Peter Galison, e Thinking About Property (2007) de Peter Garnsey ${ }^{(15)}$. Incluo ainda um grupo de obras mais recentes ou já no prelo, como por exemplo: Common Sense: $A$

(14) Todavia, para mais recentes aproximações entre a «Escola de Cambridge» e a história conceptual, veja-se em especial Melvin Richter, The History of Political and Social Concepts: A Critical Introduction, Nova Iorque, Oxford University Press, 1995; Hartmutt Lehmann e Melvin Richter (eds.), The Meaning of Historical Terms and Concepts: New Studies on Begriffsgeschichte, Washington, DC, German Historical Institute, 1996; Quentin Skinner, «Rhetoric and Conceptual Change», Finnish Yearbook of Political Thought, 2 (1998), p. 60-73.

(15) Charles Taylor, Sources of the Self: The Making of the Modern Identity, Cambridge, Mass., Harvard University Press, 1989; Martin Jay, Songs of Experience: Modern American and European Variations on a Universal Theme, Berkeley, University of California Press, 2005; Jerrold Seigel, The Idea of the Self: Thought and Experience in Western Europe since the Seventeenth Century, Cambridge, Cambridge University Press, 2005; Darrin M. McMahon, Happiness: A History, New York, Grove Press, 2006; Lorraine Daston e Peter Galison, Objectivity, New York, Zone Books, 2007; Peter Garnsey, Thinking about Property: From Antiquity to the Age of Revolution, Cambridge, Cambridge University Press, 2007. 
Political History (2011) de Sophia Rosenfeld, Toleration in Conflict (2012) de Rainer Forst, Tragic Irony: Democracy in European and American Thought de James Kloppenberg, Democracy: Representing Equality in History de Richard Bourke e Genius: A History de McMahon, bem como o meu próprio trabalho sobre as conceções da guerra civil, ao qual voltarei mais adiante ${ }^{(16)}$.

Aquilo que une estas obras é a sua ambição de construir histórias diacrónicas focadas naquilo que intitulei informalmente de "grandes ideias»: isto é, conceitos centrais nos nossos vocabulários políticos, éticos e científicos, que possuem um longo passado e que, na maioria dos casos, foram decisivamente transvalorizados em algum momento dos últimos trezentos anos. A tendência assinalada por todos estes livros foi rotulada por Darrin McMahon em «The Return of the History of Ideas?» com um importante ponto de interrogação ${ }^{(17)}$. Pode falar-se de um «regresso» porque se assemelha à antiquada «história das ideias» associada a Lovejoy e seus seguidores: ela é diacrónica, ambiciosa no que respeita à escala temporal, interdisciplinar (pelo menos no sentido em que aborda diferentes géneros de produções intelectuais) e focada em conceitos fundamentais ligados sobretudo à história Euro-Americana.

De uma maneira geral, os paralelismos podem parecer sólidos mas uma análise mais atenta revela diferenças determinantes. Nenhum historiador intelectual usaria hoje as metáforas estridentes de Lovejoy de «ideias-unidade» como elementos químicos, nem assumiria que a biografia de uma ideia pode ser escrita como se possuísse uma continuidade e identidade quase biológicas ao longo do tempo, juntamente com um ciclo de vida mais longo que o de qualquer ser humano. Pode haver uma semelhança de família entre a original história das ideias e a sua descendente homónima, mas o parentesco é artificial tendo em conta que esta nova história das ideias surgiu como resposta às críticas profundas aos métodos de Lovejoy surgidas após a sua morte

(16) Sophia Rosenfeld, Common Sense: A Political History, Cambridge, Mass., Harvard University Press, 2011; Rainer Forst, Toleration in Conflict: Past and Present, Cambridge, Cambridge University Press, 2013; James T. Kloppenberg, Tragic Irony: Democracy in European and American Thought, Nova Iorque, Oxford University Press, no prelo; Richard Bourke, Democracy: Representing Equality in History, Londres, Profile Books, no prelo; Darrin M. McMahon, Genius: A History, New York, Basic Books, no prelo.

(17) Darrin M. McMahon, «The Return of the History of Ideas?», in Darrin M. McMahon e Samuel Moyn (eds.), Rethinking Modern European Intellectual History, Nova Iorque, Oxford University Press, 2013. 
em 1962. De facto, mais do que um regresso, esta é uma reinvenção da história intelectual de longo alcance de modo a transformá-la em algo bastante diferente: um método robusto que apele a um público alargado de académicos e até de não-académicos, e que possa retomar o diálogo entre a história intelectual e outras formas de «big history». Com base nesta reinvenção, acredito que podemos conseguir a muito esperada aproximação entre a história intelectual e a longa duração.

Para justificar essa aproximação, proponho três vias que espero que ilustrem e esclareçam este novo tipo de história intelectual de longo alcance. A primeira via propõe que pensemos nesta história como uma história transtemporal, seguindo a analogia da história transnacional. A segunda via é a ideia de que esta história deve adotar um método de contextualismo seriado fazendo uso dos procedimentos caraterísticos da história intelectual anglo-americana, embora de um modo simultaneamente diacrónico e sincrónico. A terceira via é uma proposta para pensar o resultado deste contextualismo seriado transtemporal como uma «história nas ideias», de modo a distingui-la da duvidosa e desacreditada «história das ideias» associada a Lovejoy e aos seus seguidores. Depois, procurarei dar uma breve explicação do significado de cada um destes termos para depois ilustrar o modo como tenho tentado pô-los em prática na escrita de uma história de conceções da guerra civil desde a Roma Antiga até ao século XXI.

Apliquei o termo história transtemporal ao modelo de história transnacional para sublinhar os elementos de ligação e comparação ao longo do tempo, do mesmo modo que a história transnacional aborda as mesmas ligações ao longo do espaço. (Ao contrário do termo «transnacional», originalmente usado no contexto humanista da filologia de meados do século XIX, o termo «transtemporal» pertencia originalmente à anatomia e significava «que cruza as têmporas; que atravessa o lobo temporal do cérebro»: um empréstimo talvez não totalmente despropositado quando usado para descrever um modo de história intelectual) ${ }^{(18)}$. A história transnacional é simultaneamente expansiva e controlada: é expansiva porque procura deliberadamente ultrapassar as histórias das nações ou estados limitados, e é controlada

(18) Pierre-Yves Saunier, «Transnational», in Akira Iriye e Pierre-Yves Saunier (eds.), The Palgrave Dictionary of Transnational History, Basingstoke, Palgrave Macmillan, 2009, p. 1047-1055; OED, s.v., «transtemporal». 
porque geralmente aborda os processos, conjunturas e instituições que atravessaram as fronteiras destas unidades históricas ${ }^{(19)}$.

A história transnacional não nega a existência do nacional, pese embora o seu esforço por ultrapassar as determinantes deste espaço. Do mesmo modo, admito que a história transtemporal deve ser simultaneamente extensiva e delimitada: ela une contextos, momentos e períodos distintos preservando a especificidade sincrónica desses mesmos contextos. A história transtemporal não é transhistórica: não é atemporal mas está sujeita ao tempo para, deste modo, evitar os perigos da reificação e da negação da ação humana inerentes à história das ideias, abstrata e atemporal, defendida por Lovejoy, por exemplo. Assim, ao contrário da tradicional história das ideias que assumia mas não investigava o modo como as ideias viajavam material e institucionalmente ao longo do tempo, a história transtemporal sublinha os mecanismos de ligação entre diferentes momentos, preocupando-se com as questões da transmissão, tradição e receção concretas.

Esta história transtemporal atuará necessariamente por meio de um contextualismo seriado. Refiro-me à reconstrução de uma sequência de contextos distintos nos quais agentes identificáveis usaram estrategicamente linguagens existentes para atingir objetivos definíveis, tais como a legitimação e a deslegitimação, persuasão e dissuasão, construção de consensos e inovação radical, por exemplo. Pelo menos desde a revolução contextualista iniciada por Skinner em 1969, a maioria dos historiadores intelectuais que se assumem como contextualistas analisaram o contexto de um modo sincrónico e pontual, isto é, definiram-no de um modo cronologicamente estreito e implicitamente descontínuo com outros contextos. Um dos propósitos iniciais por detrás de uma interpretação tão rígida do contexto foi o de desencorajar o recurso à história das ideias baseada na abordagem de longa duração e exemplificada por Lovejoy, a qual ignorava o contexto e desvalorizava a ação dos utilizadores da linguagem. Este exercício salutar pode, contudo, ter tido como consequência não intencional o facto de os historiadores

(19) Patricia Clavin, «Defining Transnationalism», Contemporary European History, 14 (2005), p. 421-439; C. A. Bayly, Sven Beckert, Matthew Connelly, Isabel Hofmeyr, Wendy Kozol, e Patricia Seed, «AHR Conversation: On Transnational History», American Historical Review, 111 (2006), p. 1441-1464; David Armitage, «The International Turn in Intellectual History», in McMahon and Moyn, (eds.), Rethinking Modern European Intellectual History; Armitage, Foundations of Modern International Thought, Cambridge, Cambridge University Press, 2013. 
intelectuais separarem contextos semelhantes que ocorreram antes ou depois uns dos outros para criar aquilo que um crítico do contextualismo imaginou como «o comboio-correio da história que puxa períodos autossincronizados em conjuntos semelhantes a vagões» ${ }^{(20)}$.

Não há nenhuma razão válida para não conseguirmos ultrapassar essa objeção construindo passagens entre os vagões, isto é, formas de unir diacronicamente contextos reconstruídos ao longo do tempo - a um nível transtemporal - para produzir histórias de grande alcance que não sejam artificialmente vincadas nem ilusoriamente contínuas. Existem modelos para esta prática retirados, inclusive, do coração do projeto contextualista conhecido como «Escola de Cambridge». Não é, com efeito, Machiavellian Moment (1975) de John Pocock uma obra de contextualismo seriado? Ou Rights of War and Peace (1999) de Richard Tuck? Ou mesmo Genealogy of the Modern State (2009) de Quentin Skinner ${ }^{(21)}$ ? Pergunto-me agora se o contextualismo seriado não foi o método na base da minha obra The Ideological Origins of the British Empire (2000): talvez, como um historiador intelectual do tipo de M. Jourdain, eu possa agora admitir que sempre fui um contextualista seriado ${ }^{(22)}$.

Estes e outros exemplos mostram que as próprias conceções de contexto se têm tornado cada vez mais transtemporais, embora raramente tenham sido explicitamente teorizadas em termos diacrónicos. Selecionando apenas dois exemplos notáveis, o que era a tradição retórica desde Aristóteles, ou possivelmente desde o Ad Herennium, senão um contexto diacrónico e dinâmico a partir do qual Hobbes desenvolveu estrategicamente a sua conceção de linguagem?(23). Ou o que eram as longas tradições de exegese bíblica e do Hebraísmo Cristão a partir das quais os estudiosos do conceito de república hebraica construíam os seus argumentos relativamente ao republicanismo exclusivista,

(20) Herbert F. Tucker, «Introduction», in Rita Felski and Herbert F. Tucker (eds.), “Context?", New Literary History, 42 (2011), p. ix.

(21) J. G. A. Pocock, The Machiavellian Moment: Florentine Political Thought and the Atlantic Republican Tradition, $2^{\mathrm{a}}$ ed., Princeton, NJ, Princeton University Press, 2003; Richard Tuck, The Rights of War and Peace: Political Thought and the International Order from Grotius to Kant, Oxford, Clarendon Press, 1999; Quentin Skinner, «A Genealogy of the Modern State», Proceedings of the British Academy, 162 (2009), p. 325-370 (Tradução espanhola, «Una genealogía del Estado moderno», Estudios Públicos, 118 (2010), p. 5-56).

(22) David Armitage, The Ideological Origins of the British Empire, Cambridge, Cambridge University Press, 2000.

(23) Quentin Skinner, Reason and Rhetoric in the Philosophy of Hobbes, Cambridge, Cambridge University Press, 1996. 
distributismo equitativo e à tolerância religiosa? ${ }^{(24)}$. As obras de Quentin Skinner e Eric Nelson que abordam estas tradições são tão rigorosamente contextualistas quanto se possa desejar. Contudo, cada uma delas estabelece elos sincrónicos com tradições diacrónicas seculares ou mesmo milenares ainda que não pretendam reconstruir cada passo na transmissão destas tradições, como faz um tipo de trabalho mais conscientemente contextualista seriado como o que pretendo realizar ${ }^{(25)}$.

O resultado da adoção clara e consistente do contextualismo seriado seria aquilo a que chamei uma «história nas ideias». Vejo aqui um género de história intelectual na qual os episódios de luta pelo significado formam as bases de uma narrativa transtemporal construída durante um período de tempo que se estende por décadas ou até mesmo séculos. As «ideias» na base desta história não seriam entidades hipostasiadas, fazendo a sua entrada ocasional no mundo corrente a partir das esferas celestes do idealismo, mas antes pontos de foco de argumentos moldados e debatidos esporadicamente ao longo do tempo com uma ligação consciente - ou, pelo menos, demonstrável - a exemplos anteriores e posteriores de tais lutas. Assim como a história do mundo foi recentemente narrada de um modo sugestivo «em 100 objetos», também uma «história nas ideias» pode ser narrada num número finito de momentos ${ }^{(26)}$. As ideias selecionadas devem interligar-se ao longo do tempo e também na carga de significados que transportam a partir do seu diálogo com o passado e, ocasionalmente, com o futuro. Tendo em mente estes princípios algo abstratos, procurarei agora dar uma ideia da minha tentativa continuada de escrever uma «história nas ideias», transtemporal e contextualista seriada em volta dos momentos-chave na história intelectual da guerra civil desde a Roma antiga até ao presente.

O conceito de «guerra civil» é um importante candidato a uma «história nas ideias» porque tem uma história com um princípio

(24) Eric Nelson, The Hebrew Republic: Jewish Sources and the Transformation of European Political Thought, Cambridge, Mass., Harvard University Press, 2010.

(25) Veja-se também a obra The Greek Tradition in Republican Thought, Cambridge, Cambridge University Press, 2004, de Eric Nelson, que vai de Platão a Tocqueville.

(26) Neil MacGregor, A History of the World in 100 Objects, Londres, Allen Lane, 2010. 
identificável, no primeiro século a.C., mas nenhum final previsível ${ }^{(27)}$. É um conceito que resiste à reificação porque é simultaneamente valorativo e descritivo: não se pode abstraí-lo - apesar de tentativas notáveis neste sentido - mas tem de ser historiado. É também um termo indispensável ao nosso vocabulário político, embora a sua aplicação aos acontecimentos nunca seja pacífica. Isto deve-se em parte ao facto de «guerra civil» surgir tanto em discursos técnicos como no discurso corrente: qualquer um de nós pode pensar que sabe o queé «guerra civil» quando a vê (ou quando lhe falam dela), mas há múltiplas comunidades de especialistas, tais como advogados internacionais, cientistas políticos e os próprios políticos, que não terão a mesma opinião. A história do modo como o termo «guerra civil» foi usado durante mais de dois milénios é feita de continuidades semânticas e de ruturas concetuais, tendo todas elas sido contestadas em algum momento. No entanto, a sua própria ubiquidade na linguagem contemporânea contrasta fortemente com a sua quase ausência no primeiro século após a sua invenção, e a sua circulação global - através de todas as línguas europeias e a partir destas para outros grupos linguísticos - trai a sua especificidade original no âmbito do discurso jurídico romano. Tanto o conflito em volta do seu significado como o significado do mesmo conflito caraterizaram a história deste termo desde o seu início, e este continua a ser um traço distintivo da força continuada dessa história até ao tempo presente.

A «guerra civil» assemelha-se a um conceito essencialmente contestado, nos famosos termos do filósofo e circunstancial historiador das ideias, W. B. Gallie. Digo que se «assemelha» porque, contrariamente aos exemplos de conceitos aduzidos por Gallie - justiça social, arte, democracia, doutrina cristã - a «guerra civil», embora parte dos conceitos que Gallie designava por «valorativos», não é uniformemente positiva como termo avaliativo. No entanto, é internamente complexa - na verdade, como veremos, é na sua origem um oximoro; pode ser descrita de várias maneiras porque não possui uma definição a priori; é passível de revisão em circunstâncias variáveis; e sempre foi usada de modo agressivo e defensivo tanto para fins de legitimação como de deslegitimação. A sua aplicação pode variar consoante falemos de um governante ou de um rebelde, de um vencedor ou de um vencido,

(27) David Armitage, Civil War: A History in Ideas, Nova Iorque, Knopf, no prelo. 
de um governo estabelecido ou de uma terceira parte interessada ${ }^{(28)}$. Aquilo que para um governante pode parecer uma rebelião contra a sua autoridade pode ser visto como uma guerra civil pelos insurgentes que procuram derrubar essa mesma autoridade. Do mesmo modo, aquilo que os combatentes veem como uma guerra civil pode ser visto pelos observadores externos como uma insurreição, uma revolução ou simplesmente como tempos «conturbados». Esta mesma contestabilidade ajudou a tornar a guerra civil naquilo que Michel Foucault designou por «a mais desacreditada de todas as guerras» ${ }^{(29)}$.

Para mostrar a natureza essencialmente contestatória do conceito de «guerra civil» - e para demonstrar, pelo menos parcialmente, o que a minha «história nas ideias» da guerra civil significa - vejamos agora três exemplos transtemporais relativos ao modo como tem sido usado. O primeiro exemplo vem de Apiano de Alexandria, um historiador grego do séc. II d.C. que narrou as guerras civis de Roma. Apiano escreveu que, nos anos 80 a.C., o conflito entre Sula e Mário, generais concorrentes,

[...] foi o primeiro a ter lugar em Roma sem ser disfarçado de dissensão civil, mas abertamente, enquanto guerra [polemos], com trombetas e estandartes militares... Os episódios de conflito civil evoluíam da rivalidade e contendas para o assassinato e a guerra total. Este foi o primeiro exército composto por cidadãos romanos a atacar o seu próprio país como se de uma força hostil se tratasse ${ }^{(30)}$.

A descrição de Apiano tem um valor especial visto tratar-se de um historiador que se expressa em grego, uma língua e cultura que não possuíam um equivalente preciso para a expressão «guerra civil»; este era um conceito específica e reconhecivelmente romano na sua origem ${ }^{(31)}$. $\mathrm{Na}$

(28) W. B. Gallie, «Essentially Contested Concepts», Proceedings of the Aristotelian Society, 56 (1955-1956), p. 171-180. Para um resumo útil e recente da literatura posterior a Gallie, veja-se a obra de David Collier, Fernando Daniel Hidalgo e Andra Olivia Maciuceanu, «Essentially Contested Concepts: Debates and Applications», Journal of Political Ideologies, 11 (2006), p. 211-246.

(29) «[...] la plus décriée des guerres [...] la guerre civile»: Michel Foucault, carta de dezembro de 1972, in Foucault, Dits et Écrits, ed. Daniel Defert e François Ewald, 4 vols., Paris, Editions Gallimard, 1994, I, p. 42.

(30) Apiano, The Civil Wars, trad. John Carter, Penguin, Harmondsworth, 1996, p. 32-33 (I. 59-60).

(31) Nicole Loraux, The Divided City: On Memory and Forgetting in Ancient Athens, trad. Corinne Pache e Jeff Fort, Nova Iorque, Zone Books, 2002, p. 24-25, 107-08. 
genealogia intelectual da guerra civil, tal como em tantas outras coisas, todos os caminhos vão dar a Roma ${ }^{(32)}$.

Os conceitos romanos de «guerra civil» foram matéria de discussão até finais do séc. XIX. Herman Melville escreveu o epitáfio tardio dos mesmos quando assinalou a rendição em Appomattox, em 1865, com um poema que começava assim:

As águias guerreiras batem as asas,

Mas não a mando de César;

Não cantamos Roma vencida pelas próprias armas,

Como no dia da batalha de Farsalos,

Mas antes a gigantesca traição destronada

E o grande triunfo da liberdade ${ }^{(33)}$.

Assim sendo, o meu segundo exemplo é retirado do período em que as conceções romanas de «guerra civil» tinham dado lugar a um debate ainda mais confuso e polémico em torno das relações entre os conceitos de «revolução», «rebelião», «insurgência» e «guerra civil». Trata-se do trabalho de Francis Lieber, um advogado prussiano e o primeiro professor universitário norte-americano de ciência política que, em 1863, escreveu o seguinte:

Guerra civil é uma guerra entre duas ou mais zonas de um país ou estado, cada uma delas lutando pelo domínio do todo e alegando ser o seu governante legítimo. A expressão é, por vezes, também aplicada à guerra de rebelião, quando as províncias ou zonas rebeldes são contíguas às que acolhem a sede do governo ${ }^{(34)}$.

Lieber tentou ser neutro na sua definição, que forjou em plena Guerra Civil Americana, com o objetivo de incluí-la na primeira

(32) Paul Jal, La guerre civile à Rome. Étude littéraire et morale, Paris, 1963; Robert Brown, «The Terms Bellum Sociale and Bellum Ciuile in the Late Republic», in Carl Deroux, ed., Studies in Latin Literature and Roman History, 11 (2003), p. 94-120; Brian Breed, Cynthia Damon e Andreola Rossi, eds., Citizens of Discord: Rome and its Civil Wars, Oxford, Oxford University Press, 2010.

(33) Herman Melville, «The Surrender at Appomattox» (abril de 1865), cit. por Richard Thomas, «'My brother got killed in the war': Internecine Intertextuality», in Breed, Damon e Rossi, eds., Citizens of Discord, p. 302-03.

(34) [Francis Lieber,] Instructions for the Government of Armies of the United States in the Field, Nova Iorque, D. Van Nostrand, 1863, p. 25. 
codificação jurídica das leis da guerra: as famosas General Orders no. 100 do Exército da União, mais conhecidas por Código Lieber, em homenagem ao seu autor. Esta definição não tinha precedentes na literatura jurídica e foi mais tendenciosa e controversa no seu tempo do que o próprio Lieber reconheceu. Apesar de pouco ter contribuído para evitar polémicas concetuais futuras, o Código Lieber veio a tornar-se, no devido tempo, o modelo das Convenções de Genebra e Haia, assim como de sucessivos manuais de campo do exército norteamericano nos sécs. XX e XXI ${ }^{(35)}$.

$\mathrm{O}$ meu terceiro e último exemplo vem dos cientistas sociais norteamericanos Melvin Small e David Singer que, em 1972, definiram «guerra civil» do seguinte modo:

[...] combate militar prolongado, maioritariamente interno, que resulta em, pelo menos, mil mortes em combate por ano, opondo as forças do governo central a uma força insurgente capaz de [...] causar às forças governamentais, pelo menos, $5 \%$ das baixas dos insurgentes ${ }^{(36)}$.

Esta definição surgiu na sequência de um debate aceso e de muita confusão entre os cientistas sociais durante a Guerra Fria em torno da diferença entre «guerra civil» e outros tipos de «guerra interna» (motim, rebelião, revolução, insurgência). Cada um dos elementos desta definição foi incluído para marcar fronteiras e evitar a imprecisão: teria de ser uma guerra (em vez de qualquer outro tipo de violência de larga escala); teria de ser interna a um estado existente, mas não exclusivamente, de modo a poder incluir também as guerras civis que arrastavam forças externas; teria de excluir massacres e genocídios unilaterais; e deixaria em aberto as motivações dos intervenientes, ainda que sugerisse que um dos lados fosse o legítimo («forças governamentais centrais»), por oposição ao outro («uma força insurgente»).

Cada uma destas três definições que se sobrepõem - uma do séc. II, outra de meados do XIX e a terceira de finais do XX, respetivamente reflete uma era abrangente na história transtemporal da guerra civil: a

(35) Richard Shelly Hartigan, Lieber's Code and the Law of War, Chicago, Precedent Publishing, 1983); John Witt, Lincoln's Code: The Laws of War in American History, Nova Iorque, Free Press, 2012.

(36) Melvin Small e J. David Singer, Resort to Arms: International and Civil Wars, 18161980, Beverley Hills, Sage Publications, 1982, p. 210-20. 
definição de Apiano é uma conceção romana, descritiva e histórica que foi produto de uma discussão de dois séculos entre historiadores, poetas, oradores e juristas romanos em torno dos conflitos sucessivos e repetitivos da própria Roma; a de Lieber é uma conceção euro-americana, jurídica e normativa que o autor tentou remendar, na esperança de clarificar a confusão à volta do tema; e, por fim, a de Small e Singer é uma definição americana mas, em última instância, é também global, empírica e de caráter científico-social, tendo nascido da necessidade que os cientistas sociais tinham de uma definição que os ajudasse a analisar grandes volumes de informação. Todas estas três definições deixaram a sua marca no modo como hoje entendemos a guerra civil, embora cada uma delas tenha gerado controvérsia e tenha sido sobejamente discutida.

O conceito de «guerra civil» foi sempre essencialmente questionado porque, desde a sua origem, vem sendo internamente contestado. Os romanos designavam geralmente as suas guerras pelos nomes dos seus adversários (guerras anibálicas, jugurtinas, servis...) e esta prática tornou o conceito de «guerra civil» particularmente problemático. O termo foi provavelmente cunhado - optei por usar a passiva uma vez que o seu autor é desconhecido - a partir da analogia com o direito civil (ius civile), mas uma bellum civile referia-se mais precisamente a uma guerra contra cives ou cidadãos. As guerras de Roma eram, por definição, travadas contra inimigos externos ou hostes, literalmente a antítese dos que estavam vinculados à civitas pelos laços comuns da cidadania. E para ser uma guerra (bellum) teria de ser justa, o que não era, por definição, o caso de uma contenda entre concidadãos ${ }^{(37)}$.

A natureza paradoxal, oximorónica até, da bellum civile - uma guerra que não podia ser justificada enquanto tal, travada entre inimigos que não podiam ser chamados de inimigos - explica as enormes reservas dos romanos no que toca ao conceito de "guerra civil" e que se prolongaram pelo séc. I d.C. No entanto, na altura em que Apiano escreveu a história dos conflitos internos de Roma, as guerras entre concidadãos eram tão frequentes e a imagem das mesmas ficara tão claramente definida na sua memória que a descrição da marcha de Sula pela cidade reuniu unanimidade. As trombetas e os estandartes eram os sinais visíveis, a guerra

(37) Veit Rosenberger, Bella et expeditiones. Die antike Terminologie der Kriege Roms, Estugarda, Franz Steiner Verlag, 1992; Brown, «The Terms Bellum Sociale and Bellum Ciuile in the Late Republic». 
convencional o meio, e o controlo de Roma o objetivo: em geral, estas eram as marcas identificadoras de uma guerra civil e não os sinais de um mero tumulto, dissensão ou sedição. Apiano também sugeriu a existência de uma narrativa, na qual o ataque de Sula era o episódio original.

As obras de César, Salústio, Lucano, Tácito, Plutarco, Apiano, Floro e Agostinho, para mencionar apenas os nomes mais proeminentes, transmitiram versões dessa mesma narrativa por todo o mundo latino ocidental, pelo menos até finais do séc. XVIII. Existia o que se poderia chamar de narrativa republicana de guerras civis aparentemente intermináveis e recorrentes que eram consequência do próprio tecido da civilização romana: viver em civilização era estar sujeito a uma guerra civil, e sofrer uma guerra civil abria caminho a dissensões destrutivas posteriores no seio da comunidade. Paralelamente, havia também uma narrativa imperial ou augusta que seguia, em grande parte, o mesmo padrão, embora defendendo que a única cura para a patologia da guerra civil seria a restauração da monarquia ou a exaltação de um imperador. «Neste sentido», escreveu Apiano, «o Estado romano sobreviveu a todos os tipos de perturbações civis até alcançar a unidade e a monarquia»: «uma prova evidente» - concordou o tradutor para inglês em finais do séc. XVI - «de que a soberania do povo tem de acabar e ceder o lugar ao poder da monarquia» ${ }^{(38)}$. Por fim, havia também uma narrativa cristã, celebremente produzida por Agostinho, o último grande historiador romano, que apresentou a história pagã de Roma como um catálogo $\mathrm{d}^{\prime}$ «aqueles males que eram mais infernais porque internos» (quanto interiora, tanto miseriora), uma série de «discórdias civis, ou melhor, incivis» (discordiae civiles vel potius inciviles) ${ }^{(39)}$. A popularidade destas narrativas da guerra civil enquanto fenómeno repetitivo, cumulativo e transformador só diminuiu durante o período a que os historiadores chamam de «Era das Revoluções», quando outro tipo de narrativa de revoluções igualmente recorrentes, sequenciais e transtemporais - começou a destroná-la ${ }^{(40)}$. Ao mesmo tempo que revolucionários

(38) Apiano, The Civil Wars, trad. Carter, p. 4 (I. 6); [Apiano,] An Auncient Historie and exquisite Chronicle of the Romane warres, both Civile and Foren, London, Raufe Newbery e Henrie Bynniman, 1578, frontispício.

(39) Augustine, The City of God against the Pagans, ed. R. W. Dyson, Cambridge, Cambridge University Press, 1998, p. 132 (III. 23).

(40) Reinhart Koselleck, et al., «Revolution, Rebellion, Aufruhr, Bürgerkrieg», in Otto Brunner, Werner Conze e Koselleck, (eds.), Geschichtliche Grundbegriffe. Historisches Lexikon zur 
autoconscientes renomeavam as guerras civis de revoluções, não era coincidência, por exemplo, que as edições do grande poeta romano da guerra civil, Lucano, tendo sido publicadas praticamente todos os anos durante o séc. XVIII, tivessem sido interrompidas, só ressurgindo numa era mais avançada das guerras civis, em finais do séc. $X X^{(41)}$.

As conceções romanas da guerra civil começaram por ser meramente jurídicas, mas acabaram por se estender também à literatura e à história. A muito tardia redefinição jurídica de «guerra civil» criada por Francis Lieber ocorreu num contexto radicalmente diferente em meados do séc. XIX. Em 1863, o Tribunal Supremo dos E.U.A. deliberou sobre quatro casos, conhecidos coletivamente como Prize Cases, na sequência da ordem do presidente Abraham Lincoln, em abril de 1861, de bloquear os portos de Chesapeake Bay até à boca do Rio Grande devido ao facto de os estados da Confederação terem originado «uma insurreição contra o governo dos Estados Unidos». Os queixosos argumentaram que o Presidente tinha aplicado leis de guerra a uma situação em que as mesmas não eram pertinentes, uma vez que nenhuma guerra tinha sido declarada. Em nome da maioria, o juiz Robert Grier argumentou que os E.U.A. estavam, de facto, em guerra com a Confederação Sulista. «Uma guerra civil nunca é declarada abertamente; chega-se a ela acidentalmente, pelo número, poder e organização das pessoas que a causam e a levam em frente» ${ }^{(42)}$. No rescaldo dessa decisão, o general Henry Halleck, chefe do Exército da União, incumbiu Francis Lieber de redigir o primeiro conjunto de normas codificadas para a guerra terrestre. Quando Lieber enviou uma primeira versão a Halleck em fevereiro de 1863, o general apontou a falta de um elemento crucial: a definição de um tipo específico de conflito interno no qual o seu Exército esteve envolvido durante mais de um ano. Como escreveu a Lieber, «para ser mais útil no tempo

politisch-sozialen Sprache in Deutschland, 8 vols., Estugarda, E. Klett, 1972-1997, V, p. 712-14, 72627, 778-80; Roman Schnur, Rivoluzione e guerra civile, ed. Pier Paolo Portinaro, Milan, Giuffrè, 1986; David Armitage, «Every Great Revolution is a Civil War», in Keith Michael Baker e Dan Edelstein (eds.), Scripting Revolution, Stanford, Stanford University Press (no prelo).

(41) Sobre a história da receção de Lucano, vide os capítulos relevantes em Paolo Asso, ed., Brill's Companion to Lucan, Leiden, Brill, 2011.

(42) The Prize Cases, 67 E.U.A. 635 (1863); Brian McGinty, Lincoln and the Court, Cambridge, Mass., Harvard University Press, 2008, p. 118-43; Thomas H. Lee e Michael D. Ramsey, «The Story of the Prize Cases: Executive Action and Judicial Review in Wartime», in Christopher H. Schroeder e Curtis A. Bradley, (eds.), Presidential Power Stories, Nova Iorque, Foundation Press, 2009, p. 53-92. 
presente, [o Código] deve abarcar não só a guerra civil, mas também a guerra entre estados ou soberanias distintas» ${ }^{(43)}$.

No entanto, de acordo com a definição final de Lieber - «guerra entre duas ou mais zonas de um país ou estado, lutando cada uma delas pelo domínio do todo e alegando ser o seu governante legítimo»-a «Guerra Civil» Americana não foi de todo uma guerra civil. Pode ter sido travada entre duas partes do país, mas só uma delas pretendia dominar todo o território ou alegava ser o seu governante legítimo. Segundo a própria definição de Lieber, a Guerra Civil foi, na verdade, uma rebelião: «uma insurreição em larga escala e, normalmente, uma guerra entre o governo legítimo de um país e zonas ou províncias do mesmo que pretendem terminar essa aliança, criando um governo próprio». De facto, Lieber praticamente admitiu isso na segunda parte da sua definição de «guerra civil»: «por vezes aplicada à guerra de rebelião, quando as zonas rebeldes são contíguas às que acolhem os órgãos do governo» - daí, presumivelmente, em finais do séc. XIX, a designação oficial usada pela União ser Guerra da Rebelião ${ }^{(44)}$.

Não obstante as dificuldades em encontrar uma definição, o Código Lieber tornou-se a pedra angular de todo o direito humanitário internacional que se desenvolveu posteriormente, tendo sido reeditado na sua totalidade, incluindo as suas definições de «insurreição», «rebelião» e «guerra civil», para ser usado durante a guerra FilipinoAmericana em 1902, e a sua discussão em torno da definição de «guerra civil» surgiu inúmeras vezes até 1940. Foi só em 1990 que o exército norte-americano propôs uma nova definição de «guerra civil». No seu Manual de Operações de 2008, o conceito foi reduzido ao absurdo no simples parágrafo que lhe foi dedicado, entre 180 páginas densas e compactas, mencionando apenas que as guerras civis «incluem muitas vezes operações de combate importantes» e que podem resultar em «baixas substanciais» ${ }^{(45)}$. A separação entre a memória histórica norte-

(43) Anotação de Henry Halleck a Francis Lieber, A Code for the Government of Armies in the Field, As Authorized by the Laws and Usages of War on Land, «Printed as manuscript for the Board appointed by the Secretary of War» (fevereiro de 1863), p. 25-[6], The Henry E. Huntington Library, San Marino (doravante designada por HEH), 243077.

(44) [Lieber,] Instructions for the Government of Armies of the United States in the Field, p. 25; [Estados Unidos, Departamento de Guerra,] The War of the Rebellion: A Compilation of the Official Records of the Union and Confederate Armies, 70 vols. (Washington, DC: US Government Printing Office, 1880-91).

(45) Departamento do Exército dos Estados Unidos, Manual de Campo 3-0 (27 de fevereiro de 2008), § 2-67: www.army.mil / fm3-0 / fm3-0.pdf. 
americana dos seus próprios conflitos internos e a sua experiência de guerras civis no estrangeiro estava concluída.

A transição global e progressiva de guerra interestadual para intraestadual após 1945, aliada à popularidade das ciências sociais positivistas e às crises de descolonização, conduziram a novas pressões para uma definição do que era, e do que não era, uma guerra civil. A partir dos anos 1960, os cientistas sociais norte-americanos empenharam-se cada vez mais na interpretação do que era geralmente chamado de "guerra interna», uma categoria que abrangia desde a guerrilha e as insurgências, às guerras civis, golpes e revoluções ${ }^{(46)}$. A expansividade da categoria suscitou preocupação quanto à falta de foco teórico e uma insatisfação com os exemplos dados, que eram demasiado heterogéneos para serem codificados ou enumerados. Os dados não podiam ser teorizados e às teorias faltavam dados que as fundamentassem.

Foi para resolver este dilema que Melvin Small e David Singer criaram a terceira definição de «guerra civil» que citei anteriormente. Os dois estudiosos exigiam uma definição quantitativa em vez de qualitativa «para minimizar as tendências subjetivas»e, mais diretamente, para «facilitar a criação de um conjunto de dados», como forma de fugir ao que pensavam ser um labirinto concetual de definições inconsistentes e concorrentes de «guerra civil»» ${ }^{(47)}$. O grande problema desta definição é o número de conflitos que não abrange. A sua margem de 1000 mortos em batalha por ano excluiria o Conflito na Irlanda do Norte, no qual a taxa de mortalidade foi de cerca de 3500 baixas entre 1969 e 2001, com um pico de 479 em 1972. A condição de ser «principalmente interna» foi especificada como sendo «interna à metrópole», para excluir deliberadamente as guerras pós-coloniais de libertação nacional como a Guerra de Independência Argelina. Apesar do esforço em ser neutra e objetiva, esta ideia de guerra civil era, na realidade, extremamente contingente e questionável ${ }^{(48)}$. Parafraseando Winston Churchill, esta era talvez a pior definição de «guerra civil» que

(46) Harry Eckstein, «On the Etiology of Internal Wars», History and Theory, 4 (1965), p. 33-63; Jesse Orlansky, The State of Research on Internal War, Research Paper P-565, Arlington, VA, Institute for Defense Analyses, Science and Technology Division, 1970.

(47) Small e Singer, Resort to Arms, p. 210.

(48) Jan Angstrom, «Towards a Typology of Internal Armed Conflict: Synthesising a Decade of Conceptual Turmoil», Civil Wars 4 (2001), pp. 93-116; Nicholas Sambanis, «What 
se poderia imaginar, tirando todas as outras que foram sendo propostas nos últimos dois séculos. Isto seria praticamente irrelevante não fosse o facto de esta permanecer a definição padrão entre os cientistas sociais, estando por isso, na base da informação fornecida a instituições como o Banco Mundial e o Departamento de Estado Norte-Americano, na altura de determinar os níveis de risco nacional na distribuição de ajuda ou de considerar as possibilidades de uma intervenção humanitária em conflitos considerados «civis».

Escolhi estes três exemplos-chave a partir da minha «história nas ideias» para ilustrar as dimensões sincrónica e diacrónica deste género emergente. Cada instância está envolvida num diálogo consciente com a história concetual e experiencial da guerra civil. Por ter escrito em grego, Apiano foi compelido a assimilar semanticamente as guerras civis de Roma ao termo grego emphylia, ainda que a sua descrição desses conflitos, talhada com precisão, mostre o enorme fosso entre a palavra e o conceito, e entre as visões grega e romana de luta civil ${ }^{(49)}$. Francis Lieber investigou o corpus do direito internacional em busca de uma definição jurídica de «guerra civil», embora sem sucesso. Também ele teve de a distinguir de «revolução», «rebelião» e «insurreição»- que não são conceitos completamente assimétricos ao de «guerra civil»» ${ }^{(50)}$ - num esforço para melhorar a definição de um conflito específico, dentro de um contexto jurídico estreitamente definido, mas com vista à humanização da guerra no futuro. Por fim, Singer e Small procuraram transcender determinantes contextuais para criar uma definição transhistórica de «guerra civil» que revelasse apenas as marcas do seu nascimento altamente contingente. No entanto, a sua conceção permanece e floresce, até hoje, numa tensão

is Civil War? Conceptual and Empirical Complexities of an Operational Definition», Journal of Conflict Resolution, 48 (2004), p. 814-58.

(49) Paula Botteri, «Stásis: Le Mot grec, la chose romaine», Mêtis, 4 (1989), p. 87-100.

(50) Reinhart Koselleck, «The Historical-Political Semantics of Asymmetric Counterconcepts», in Reinhart Koselleck, Futures Past: On the Semantics of Historical Time, trad. Keith Tribe, Nova Iorque, Columbia University Press, 2004, p. 155-191; Kay Junge e Kirill Postoutenko (eds.), Asymmetrical Concepts After Reinhart Koselleck: Historical Semantics and Beyond, Bielefeld, transcript Verlag, 2011. 
com conceções jurídicas de "guerra civil», em última instância originárias de Lieber, e também históricas, cujas raízes são marcadamente romanas.

Mas os exemplos não são mais do que isso mesmo e os sintomas não podem confundir-se com sistemas. Até a minha iniciativa de combinar uma contextualização próxima e sincrónica com análises diacrónicas mais amplas numa abordagem de longa duração pode bem parecer demodé e anacrónica, em vez de elegantemente avant-garde. A acumulação manual e a análise de fontes, às quais os historiadores intelectuais estiveram habituados durante um século (e outros historiadores por muito mais tempo), não estão a tornar-se obsoletas mas afiguram-se cada vez mais incompletas: uma «leitura distante» de largos volumes de fontes suplementa uma leitura próxima, embora não a possa substituir ${ }^{(51)}$. Os efeitos da revolução digital estão só a começar a notar-se entre os historiadores intelectuais, mas serão com toda a certeza transformadores no que toca à vasta quantidade de materiais disponíveis para análise e ao conjunto de tecnologias ao seu alcance para resolver problemas antigos e propor novas problemáticas.

Vastas coleções de fontes que, até há pouco tempo, teriam levado uma eternidade (ou mais) a um só estudioso a recolher estão hoje disponíveis a alunos de licenciatura e ao público geral sob a forma de coleções e bases de dados digitais. O Google Books, o Internet Archive, o HathiTrust Digital Library, a Open Library e em breve a Digital Public Library of America mencionando apenas os mais extensos de entre as fontes em língua inglesa e de acesso livre - oferecem versões pesquisáveis de materiais históricos que anteriormente só estavam acessíveis a investigadores credenciados e disponíveis em repositórios físicos. Em breve, graças a estas iniciativas, ao projeto Europeana e a outras bibliotecas digitais nacionais, todos os materiais impressos - pelo menos, nas línguas ocidentais - entre 1455 e 1922, poderão ser lidos e, na sua maioria, pesquisados. Esta cornucópia de materiais digitais não se restringe apenas às línguas vivas dos últimos 500 anos: aproximadamente um bilião de palavras latinas entre 2000 a.C. e 1922 d.C. foram já digitalizadas, «eclipsando o corpus do latim clássico em várias ordens de grandeza»e «possivelmente abrangendo o maior intervalo histórico de qualquer coleção de textos principal conhecida até hoje». Esta coleção

(51) Franco Moretti, «Conjectures on World Literature», New Left Review, 1 (2000), p. 56-58; Moretti, Graphs, Maps, Trees: Abstract Models for Literary History, London, Verso, 2005. 
não organizada não pode ser usada inocentemente ou levianamente. Porém, a sua extensão e âmbito ilustram as possibilidades inesgotáveis para a investigação no âmbito da longa duração que o fenómeno da digitalização oferece ${ }^{(52)}$.

Existem ferramentas digitais para a investigação na área das humanidades há mais de meio século: «Em cerca de 1955, Deus concedeu aos homens a graça de inventar a fita magnética», escreveu Roberto Busa, S.I., um pioneiro do humanismo computacional ${ }^{(53)}$. Mas o seu poder e variedade expandiram-se, mais recentemente, para a categoria das «humanidades digitais», com novas técnicas para a quantificação de informação textual lado a lado com novos meios de visualização e análise espacial. As ferramentas mais populares até ao momento são o N-gram Viewer, que revela padrões gráficos de ocorrência de palavras no corpus da Google Books, com pelo menos $4 \%$ de todos os livros publicados em inglês, espanhol, hebraico e outras línguas, desde 1800, e o Bookworm, que permite uma análise semelhante dos acervos da Open Library e do Internet Archive ${ }^{(54)}$. Até ao momento, estas ferramentas não são conclusivas, mas apenas indicativas. Podem sugerir questões mas não fornecem respostas isoladas a partir de outras formas de imersão e comparação textual. As bases de dados nas quais se apoiam não estão ainda completas, nem estão totalmente disponíveis para leitura, variando também em abrangência e credibilidade. Porém, desde que tratadas atentamente e suplementadas com leituras aprofundadas de amostras de fontes, as pesquisas por palavras-chave podem levar a conclusões sólidas e apontar o caminho para novas questões. Nesta base, outros procedimentos tradicionais da história intelectual - como a análise concetual e a contextualização - podem também ser postos em prática com ainda mais confiança na solidez das generalizações sobre mudanças qualitativas e quantitativas ao longo do tempo.

(52) David Bamman e David Smith, «Extracting Two Thousand Years of Latin from a Million Book Library», Journal on Computing and Cultural Heritage 5, no. 1 (1 abril 2012), p. 1-13.

(53) Roberto A. Busa, «Foreword: Perspectives on the Digital Humanities», in Susan Schreibman, Ray Siemens e John Unsworth, eds., Companion to Digital Humanities, Oxford, Blackwell Publishing, 2004, p. xvii.

(54) Michel, Jean-Baptiste, Yuan Kui Shen, Aviva Presser Aiden, Adrian Veres, Matthew K. Gray, Joseph P. Pickett, Dale Hoiberg, et al. «Quantitative Analysis of Culture Using Millions of Digitized Books», Science, 331, nº 6014 (14 jan. 2011), p. 176-182. 
Até para os humanistas analógicos mais tradicionais, a promessa das humanidades digitais de transformar o trabalho dos historiadores intelectuais é fortíssima. A disponibilidade crescente de corpora textuais consideravelmente maiores, juntamente com as ferramentas para os analisar, permitem aos historiadores estabelecer as convenções que moldaram a inovação intelectual e, consequentemente, mostrar a atuação da vontade individual no contexto das estruturas coletivas. Com maior flexibilidade na pesquisa e recolha de informação contextual é possível descobrir mais precisa e claramente os momentos de rutura e os caminhos de continuidade. Em suma, hoje temos as ferramentas metodológicas e os meios tecnológicos para ultrapassar a maior parte, se não a totalidade, das objeções tradicionais ao casamento entre a história intelectual e a abordagem da longa duração. Podemos, pelo menos, voltar a estudar as grandes ideias a uma grande escala. 